\title{
Tanto todo
}

\section{Therefore all}

\section{Portanto todos os}

\author{
Marta Núñez ${ }^{1}$ \\ ${ }^{1}$ Licenciada en filología hispánica. Escritora. \\ Cómo citar este relato en edición digital: Núñez, M. (2014) La calle de la Lona. Cultura de los Cuidados (Edición digital) 18, 40. \\ Disponible en: http://dx.doi.org/10.7184/cuid.2014.40.04> \\ Correspondencia: Marta Núñez. C/Mediodía, 21. 02691, Bonete (Albacete) \\ Correo electrónico:mnd-88@hotmail.com \\ Recibido: 21/07/2014; Aceptado: 13/09/2014
}

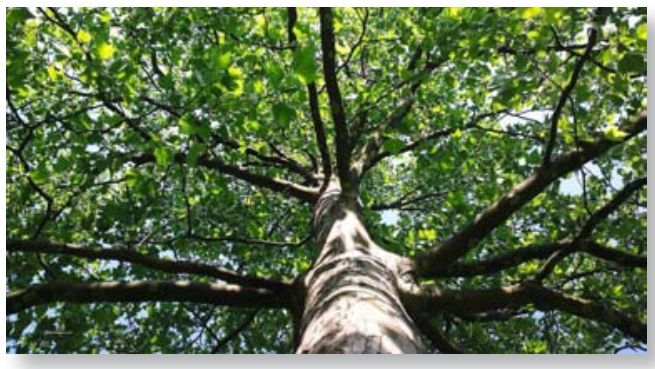

\section{ABSTRACT}

These poems are inspired by the sonnet "Life" by José Hierro, whose verses serve title to these four compositions, presented as a game between "All" and "Nothing", two terms while antagonistic, complementary because man will be familiar with the reality of "All", provided there lying on his face in utter nihilism of "Nothing", and vice versa.

Taking as its starting point the sonnet "Life" by José Hierro, whose verses serve title to these four compositions, presented as a game between "All" and "Nothing", two terms while antagonistic, complementary because man will be familiar with the reality of "All", provided there lying on his face in utter nihilism of "Nothing", and vice versa.

If we take these poems as an up gradation as to the meaning of life, we can see that, although from the first poem we find many references to death and the meaninglessness of life, once we got to the fourth poem "Both everything" the reader can see a glimmer of hope in these "last kiss", "because they do see the desired tomorrow". It is known that the lovers die, humans will die but unlike the final line of the poem Iron "after so much all for nothing", this effort will not be in vain. Life is a constant suffering, a struggle for life Darwinian manner.

The "Nothing" is hopeless, but not lack the "All" wrought daily, those little things that become, over time, momentous.

\section{RESUMO}

Estes poemas são inspirados pelo soneto "Life", de José Hierro, cujos versos servem título a estes quatro composições, apresentado como um jogo entre "All" e "Nothing", dois termos antagônicos, enquanto, complementar porque o homem vai estar familiarizado com a realidade de "All", desde que encontra-se em seu rosto no niilismo total de "Nada", e vice-versa.

Tomando como ponto de partida o soneto "Life", de José Hierro, cujos versos servem título a estes quatro composições, apresentado como um jogo entre "All" e "Nothing", dois termos antagônicos, enquanto, complementar porque o homem vai estar familiarizado com a realidade de "All", desde que encontra-se em seu rosto no niilismo total de "Nada", e vice-versa.

Se tomarmos esses poemas como uma gradação quanto ao significado da vida, podemos 
ver que, apesar de o primeiro poema encontramos muitas referências à morte e a falta de sentido da vida, uma vez que chegamos ao quarto poema "Tanto tudo" o leitor pode ver um vislumbre de esperança nestes "último beijo", "porque eles vêem o amanhã desejado". Sabe-se que os amantes morrem, os seres humanos morrerão, mas ao contrário da linha final do poema de Ferro "depois de tanto tudo por nada”, esse esforço não será em vão. A vida é um sofrimento constante, uma luta pela maneira darwiniana vida.

O "Nada" é impossível, mas não falta a "All" forjado diária, essas pequenas coisas que se tornam, ao longo do tempo, importante.

\section{RESUMEN}

Tomando como punto de partida el soneto "Vida" de José Hierro, cuyos versos servirán de título a estas cuatro composiciones, que se presentan como un juego entre el "Todo" y la "Nada", dos términos a la vez que antagónicos, complementarios, pues el ser humano será conocedor de la realidad del "Todo", siempre y cuando haya caído de bruces en el nihilismo más absoluto de la "Nada", y viceversa.

$\mathrm{Si}$ tomamos estos poemas como una gradación ascendente en cuanto al sentido de la vida, podemos observar que, aunque desde el primer poema encontremos multitud de referencias a la muerte y al sinsentido de la vida, una vez que llegamos al poema cuarto "Tanto todo", el lector podrá observar un atisbo de esperanza en esos "últimos besos”, "pues ellos sí verán el deseado mañana”. Es sabido que los amantes morirán, el ser humano morirá pero, al contrario del verso final del poema de Hierro "después de tanto todo para nada", aquí el esfuerzo no será en balde. La vida es un sufrimiento constante, una lucha por la vida a la manera darwinista.
La "Nada" es irremediable, pero no por ello carecemos del "Todo" forjado a diario, de esas pequeñas cosas que se convierten, con el paso del tiempo, en transcendentales.

\section{TANTO TODO}

Después de todo, todo ha sido nada,

Después de nada, o después de todo después de tanto todo...

JOSÉ HIERRO

(HIERRO, José. Cuadernos de Nueva York, Hiperión, 1998.)

\section{DESPUÉS DE TODO}

Adiós, parte sagrada.

Era lo acordado.

Te pesa la historia.

Parten los fuertes de corazón.

No hay criba para ti.

Me dijiste adiós.

Era parte del trato.

Cuando me rozas la mano,

invisiblemente fría

contemplo la vida que no es,

la mirada incierta,

el labio abierto al tiempo,

los años que nos pesan.

Oigo las palabras que se fueron,

o que nunca estuvieron,

ya da igual.

Y quiero arañar mi herida,

volver allí, donde entonces,

creía en la eternidad,

y pasear por el parque

y decirte

lo que de sobra ya sabes.

Me pides que me lo calle. 
Que te basta el silencioso grito,

Que no deben oírnos.

Es también parte del trato.

Todavía no entiendo por qué

firmamos ese acuerdo con la muerte.

\section{CUANDO TODO SE ACABE}

Cuando todo se acabe...

nos refugiaremos en los recuerdos,

como hace el anciano en su sillón.

Haremos el equipaje,

pero, esta vez, para siempre.

Sorberemos ese último café,

lentamente...

Sostendremos esa calma aparente:

firmeza en los ojos,

tersura en los labios.

Paso equívoco hacia la salida.

¡No mires hacia atrás!...

Pero será demasiado tarde.

De nuevo, Orfeo volverá a perder a su Eurídice.

Ya se sabe, la historia siempre,

siempre se repite.

Sólo cambian los actores.

\section{DESPUÉS DE NADA}

Quiero llorar mi pena

$y$ te lo digo

en un atardecer fusilado

por mis ánimos corroídos.

Misericordia exijo

o la hoguera eterna

de Mefistófeles increpo.

Que el alba sucumba

y con ella,

el galope de mi cuerpo

aborrecido y aborrecible.

Regresa o finiquita

la agonía de mi vivir.

El castigo sin venganza

que aún cuenta con la esperanza de este ser aniquilado

en un tiempo equivocado.

Largo domingo de desolación,

de aullido interminable.

Desatendido corazón

que sólo siente el Nevermore

como el cuervo de un tal Poe.

\section{TANTO TODO}

Probemos a amarnos

en silencio

extiende tu mano hacia

mi mejilla. Olvida

el camino recorrido y párate,

justo ahí, en mi oscura inocencia.

Transitemos la misma senda, en la que las almas se unen gritando al unísono que hoy, por fin, son libres.

No habrá un mañana para nosotros, insomnes pecadores, que creímos en la luz eterna, en amores sin límites, en cimientos siempre firmes, en los ires y venires de esta vida de encuentros furtivos $\mathrm{y}$, casi siempre, insanos.

Amor, ahora que ya sabes

que hemos de morir,

que lo nuestro tiene

los minutos contados, alegrémonos

y demos gracias por estos

últimos besos,

colmados de gracia divina,

pues ellos sí verán el deseado mañana,

pues ellos sí serán contados

cuando las cenizas se apoderen

de nuestros hoy todavía

serviles en esto del amor. 